\title{
Experimental study regarding the influence of fibre to matrix compatibility on general performance of Fibre Engineered Cementitious Materials (FECM)
}

\author{
Anamaria Mircea ${ }^{1,2^{*}}$, Călin Mircea $^{2}$, Henriette Szilágyi ${ }^{2}$, Cornelia Baeră $\breve{3}^{3}$ and Andreea Hegyi ${ }^{2}$ \\ ${ }^{1}$ N.I.R.D. URBAN-INCERC, Cluj-Napoca Branch, 400524, Calea Florești 117, Cluj-Napoca, Romania \\ ${ }^{2}$ Technical University of Cluj-Napoca, Civil Engineering Faculty, 400020, C-tin Daicoviciu 15, Cluj-Napoca, Romania \\ ${ }^{3}$ N.I.R.D. URBAN-INCERC, Timișoara Branch, 300223, Traian Lalescu 2, Timișoara, Romania
}

\begin{abstract}
Fibre Engineered Cementitious Materials (FECM) represent composites with similar overall performance as Engineered Cementitious Composites (ECC), namely developing strain hardening behaviour under loading, which generates the material capacity of high deformability. The pattern of multiple microcracks successively developed under increasing loading is proved to be the key of material self-consolidating potential and ability to support loads after the first crack occurrence. The matrix to fibre compatibility is considered to be one essential parameter controlling the multiple micro-cracking pattern (MC) and consequently, the strain hardening effect in the material. Factors like fibre type and reinforcement percent in the mixture represent sensitive variables, with major influence for matrix to fibre compatibility and overall performance of the composite. Cement based materials, whose compositional heterogeneity traditionally represents a lack in their regular usage, can be valorised and designed to produce the width controlled cracking typology, beneficial for material behaviour. This paper presents an experimental study on the fibre to matrix compatibility effect in the FECM design and producing process. Several types of dispersed reinforcing typologies for FECM development are experimentally tested and analysed. The results confirm the importance of matrix to fibre compatibility in enhancing superior material performance: physical, mechanical and even durability (Self-Healing potential evaluation).
\end{abstract}

\section{Introduction}

Fibre Engineered Cementitious Materials (FECM) are a strain hardening type of fibre reinforced composite designed, cast, evaluated and eventually tailored for a better overall physical and mechanical performance at Incerc Cluj-Napoca, in the last years. The compositional design of FECM considered the ECCs concept [1] as a starting point of their development, namely the ability to develop high deformability under loading, due to the controlled microcracking mechanisms under loading. Consequently, this unique mechanical performance is achieved, distinct from the classical cement-based composites and best emphasised under tensile loading. Brittle failure, as a specific feature of classic cementitious composites, is thus avoided, opening the path to a new typology of building materials, characterised by the strain hardening performance under loading.

The matrix to fibre compatibility is proved to be one essential parameter controlling the multiple microcracking pattern (MC) and consequently the strain hardening effect in the material, which is one of the most important compositional design considerations [1, 2]. Fibre type and also the dispersed reinforcement percentage of the cementitious matrix represent essential factors, influencing the material performance in developing the strain hardening, metal like behaviour, under loading.

\section{Fibre Engineered Cementitious Materials (FECM) - design approach}

\subsection{Strain hardening behaviour}

The ECC design approach is essentially related to the development of a succession of restricted width cracks (generally bellow $100 \mu \mathrm{m}$ ) under load increase This cracking pattern, assimilated to the High-Performance Fibre-Reinforced Cementitious Composites (HPFRCC) and particularly to the Strain Hardening Cementitious Materials (SHCM), contradicts the general, concrete typical failure mode, produced via one sudden crack with large opening and associated with a significant strength drop, (Fig. 1). The intermediate material typology, namely Fibre Reinforced Concrete (FRC) develops a quasi-brittle, tension softening response under loading. Small quantity fibres, specific to FRC, may have a positive effect in counteracting drying shrinkage cracking and also sudden, brittle failure, but still, one crack formation would enlarge under loading and will not provide the deformability of the material. 


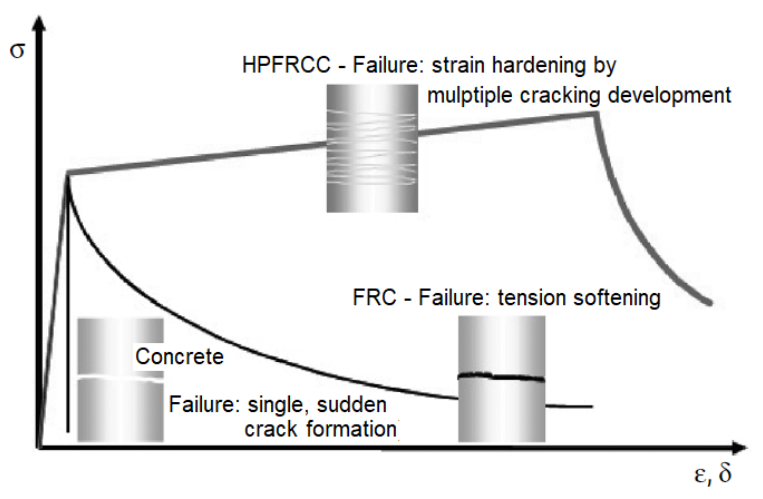

Fig. 1. Failure typology under uniaxial loading for cementitious materials: concrete, FRC and HPFRCC [1, 3]

In order to achieve the strain hardening typology $[4,5,6$, $7,8,9,10]$, two criteria have to be simultaneously satisfied: a) the strength criterion; b) the energy criterion. The first criterion determines the micro cracks' debut, from the inherent flaws (derived from the heterogeneity of the cementitious matrix with dimensions ranging from nano- to millimetre scale), before the tensile load $\left(\sigma_{\mathrm{cs}}\right)$, exceeds the maximum bridging capacity of the fibre $\left(\sigma_{0}\right)$ : $\sigma_{0} \geq \sigma_{\mathrm{cs}}$. The second criterion considers an energetic balance within several simultaneous mechanisms occurring within the matrix, like absorption, sliding and bridging, debonding and friction [2]. It entirely depends on the fibre to matrix interface, and thus their compatibility, which generates the steady state cracking pattern, namely the constant, small width along the crack length, as opposed to the unstable crack formation (the Griffith crack, with crack opening varying over their length).

It is generally proven that the fibre to matrix compatibility emphasised through their interface, depending on matrix and fibre particular, intrinsic, characteristics is essential for the material strain hardening behaviour under loading $[1,2]$.

The current experimental procedure validates the importance of these parameters.

\subsection{FECM development}

The development of FECM at Incerc Cluj-Napoca, as specified above, had as a starting point Li's ECCs and later on, considering Snoeck et al's [1, 2, 11, 12] observations for mix proportions and mixing technology, successive compositional adjustments were introduced, also based on local typology of raw materials [13, 14].

The main goal was developing FECM mixes with strain hardening behaviour by using easily available local raw materials in order to facilitate future potential technological transfer to the Romanian construction industry. In the same time, the high fly ash content of the FECM mix design, increases substantially the potential of the concept, considering the large fly ash production on Romanian territory and the very little amount of its use in the construction industry, opposing its conversion into waste $[15,16]$.

At the same time, the evaluation of the possible integration of Polypropylene fibres of local source
(PP_hyb), as a reliable alternative to the lubricated Polyvinyl Alcohol (PVA) fibres, as dispersed reinforcement of the cementitious matrix, represents an important step of the research [13].

\section{Experimental procedure - materials and methods}

The experimental procedure is elaborated in order to support a pertinent comparative analysis among several FECM mixes, where the variable is the fibre type in order to evaluate this parameter influence on the composite strength (flexural and compressive) and also the strain hardening potential by the means of a four point bending test (4PB). The influence of fibre content is also considered.

\subsection{Backgrounds of research}

The first trials to introduce the PP fibres (of local source), as potential replacement for the lubricated PVA fibres, already proved to be efficient $[1,2,17]$, but less accessible from the economic point of view and showed initial, early age, good results (Fig. 2, a), [14].

a)

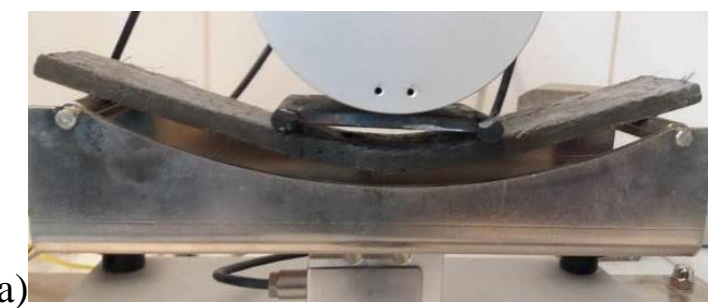

b)

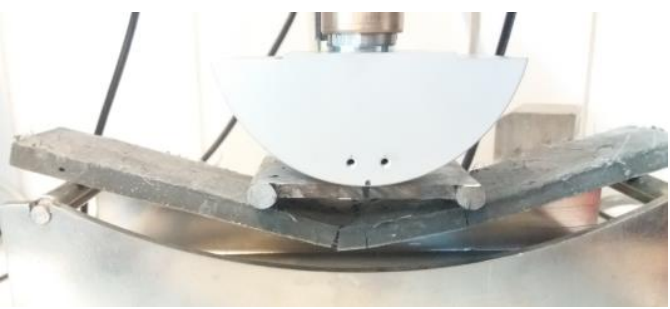

Fig. 2. Mid-span maximum deflection under 4PB test performed on: a) early age (7 days) specimens [14]; b) 28 days specimens

The 4PB performed on PP-FECM coupons specimens at the age of 28 days did not confirm the expected results (Fig. 2, b), as the material became brittle and rigid, developing just a limited number of cracks (max. 2) that widened considerably under loading, leading to failure. Still, the specimens did not break completely, the bridging effect of fibres preventing integrity loss.

The current study includes some adjustments regarding the mix design, in terms of raw materials and secondary addition changes. All changes are described below, in the raw materials paragraph.

\subsection{Raw materials}

The raw materials used for the FECM mixes are mainly provided by local producers. 
The ECC binding system represents a combination of cement (C) and a high fly ash (FA) content. The specific ratio $\mathrm{FA} / \mathrm{C}$, which usually can vary for ECC mixes from 1.0 to 1.2 or even higher $[1,2,13,17]$, was 1.2 for the FECM mixes of the current study.

The cement used was the regular Ordinary Portland Cement (OPC), namely CEM I $42.5 \mathrm{~N}$ (Fig. 3, a). The class F Fly-Ash (FA), provided by a local power station (Fig. 3, b) is characterised by the XRF analysis presented in Table 1.

a)
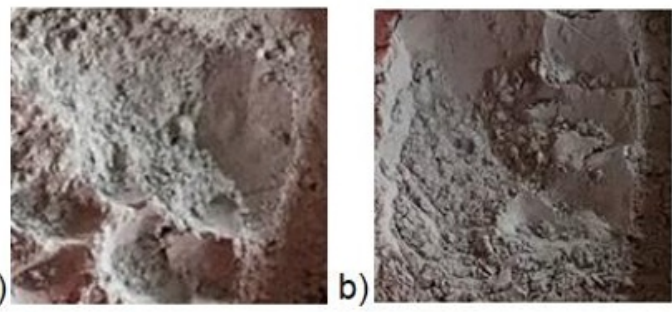

Fig. 3. The binding system: a) Cement $42.5 \mathrm{~N}$, (C) b) Class F Fly Ash, (FA)

Table 1. XRF analysis data for the fly ash samples.

\begin{tabular}{|c|c|c|c|c|c|}
\hline \multicolumn{7}{|c|}{ FA Oxides, \% } \\
\hline $\mathrm{SiO}_{2}$ & $\mathrm{Al}_{2} \mathrm{O}_{3}$ & $\mathrm{Fe}_{2} \mathrm{O}_{3}$ & $\mathbf{C a O}$ & $\mathbf{M g O}$ & $\mathrm{SO}_{3}$ \\
\hline 53.61 & 26.16 & 7.58 & 2.42 & 1.49 & 0.26 \\
\hline $\mathrm{Na}_{2} \mathrm{O}$ & $\mathbf{P}_{2} \mathrm{O}_{\mathbf{5}}$ & $\mathrm{TiO}_{2}$ & $\mathrm{Mn}_{2} \mathrm{O}_{3}$ & L.O.I. & - \\
\hline 0.59 & 0.12 & 1.04 & 0.08 & 3.57 & - \\
\hline
\end{tabular}

The polymeric fibres used were of two types: the highly performing Polyvinyl Alcohol (PVA) fibres lubricated (by $1.2 \%$ mineral oil) and provided by Kuraray, Japan. The PVA-FECM is presently developed as a control mix, in respect with the PP-FECM would be evaluated further on regarding the relevant material features previously mentioned. The second type of fibres were Polypropylene (PP_hyb), namely a combination of two types of PP fibres, provided by a local producer.

PVA fibre (Kuralon K-II fibre RECS15x8) characteristics, in accordance with the data sheet provided by the producer were as follows: diameter $5.0 \pm 3.0$ dtex, cut length $-8.0 \pm 1.0 \mathrm{~mm}$ ), tensile strength $12.0 \pm 2.5 \mathrm{cN} / \mathrm{dtex}$, converted to $1560 \pm 325 \mathrm{MPa}$, Elongation - $6.5 \pm 1.5 \%$, Modulus - $320 \mathrm{cN} / \mathrm{dtex}$.

PP1 fibres - RoWhite represents 100\% Virgin Polypropylene, with modest mechanical properties and usually used for shrinkage prevention; the basic characteristics are as follows: shape - monofilament, Density - $910 \mathrm{~kg} / \mathrm{m}^{3}$, tensile strength - $300 \mathrm{MPa}$, ut length - $6 \mathrm{~mm}$, colour - white, Absorption - none. The general conformity is specified in accordance to EN 14889-2 [18].

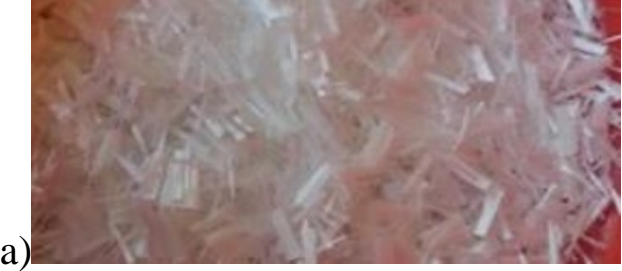

b)
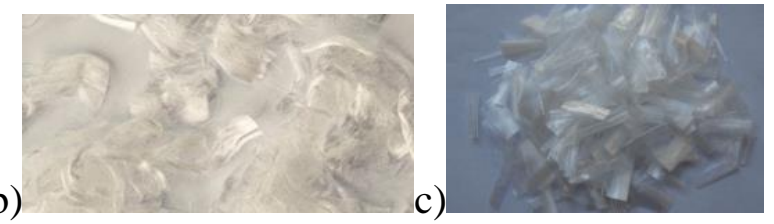

Fig. 4. Polymeric fibres: a) PVA Kuralon K-II fibre (RECS15x8) (Kuraray, Japan); b) PP RoWhite (PP1); c) ECONO NET (PP2)

PP2 fibres - Econo Net represents 100\% Virgin Polypropylene, with increased mechanical properties (for impact and wear resistance) and also used for shrinkage prevention; the basic characteristics are as follows: shape fibre network, density - $910 \mathrm{~kg} / \mathrm{m}^{3}$, tensile strength - 90 $110 \mathrm{ksi}(620-758 \mathrm{MPa})$, cut Length - $19 \mathrm{~mm}$, colour white, high acid resistance, absorption - none. The general conformity is specified in accordance with ASTM C-1116 [19].

The PP1/PP2 ratio, $1 / 3$, is considered optimum for the PP hyb FECM mix design.

The fibre content in the mix was generally $2 \%$ (by volume). A supplementary PP_hyb_FECM mix was developed considering a higher fibre content, namely $2.9 \%$ (by volume), in order to evaluate the influence of tis parameter on the overall material performance.

The Aggregate is represented by fine silica sand (FSS) provided by the traditional producer Bega Minerale SA (Cluj, Romania); the maximum grain size was $0.3 \mathrm{~mm}$ (Fig. 4, a). The FSS aggregate replaced the initially used silica sand (SS), provided by same company and with the maximum grain size of $0.5 \mathrm{~mm}$. This change was performed for a better packing of the matrix and a superior MC development under loading, in accordance to Snoeck [2].

The mix packing optimisation included another replacement, related to the lime powder, used as secondary addition to the composite [Cracovia]. Initially, inert limestone filler (L) was added to the mix in order to control the potential bleeding and to generally improve the fresh state characteristics (fibre balling and bleeding prevention, homogeneity and the creamy aspect of the mix), and the hardened characteristics as well (packing of the matrix, fine particle content increase, and extra source for calcium carbonate $\left(\mathrm{CaCO}_{3}\right)$ precipitation and consequently increase of crack closing efficiency (Self-Healing potential of the material)). 
a)
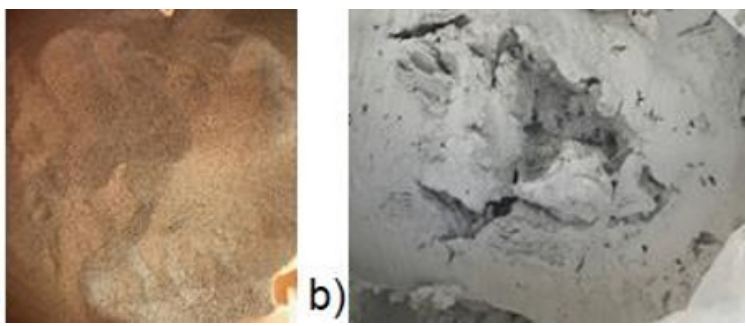

Fig. 4. Raw materials: a) Aggregate, Fine Silica Sand (FSS); b) Limestone Slurry (SL)

The slurry lime (Fig. 4, b) a lime paste with determined water content, provided as a waste of a local industry, was tested and considered proper to replace the lime powder addition. The total water adjustment in the mix was performed considering the actual water content of the lime paste.

The low water to binder ratio (W/B), essential for material performance, was maintained as low as possible by means of the polycarboxylate superplasticizer Glenium 51 (HRWR), (BASF).

\subsection{Mix design}

Table 2 presents the mix proportions of the FECM mixes (PVA- and PP_hyb-) namely the specific ratios with respect to the cement $(\mathrm{C})$ content $(\mathrm{C}=1.0)$, for optimum emphasising of the design process. Three FECM mixes are considered for the current study: the reference, namely the PVA-FECM, containing $2 \%$ (by volume) PVA lubricated fibres; 2.0 PP_hyb-FECM, containing 2\% (by volume) PP_hyb fibres; and the mix with increased content of PP, namely 2.9 PP_hyb-FECM, containing 2.9\% (by volume) PP_hyb fibres.

Table 2. Mix proportions of FECM.

\begin{tabular}{|c|c|c|c|}
\hline \multirow{2}{*}{$\begin{array}{c}\text { Compo } \\
\text { nents }\end{array}$} & \multicolumn{3}{|c|}{ FECM Mixes } \\
\cline { 2 - 4 } & $\begin{array}{c}\text { FSS-SL-PVA- } \\
\text { FA/C (1.2) }\end{array}$ & $\begin{array}{c}\text { FSS-SL-PP(2.0)- } \\
\text { FA/C (1.2) }\end{array}$ & $\begin{array}{c}\text { FSS-PP(2.9)- } \\
\text { FA/C (1.2) }\end{array}$ \\
\hline C* & 1.0 & 1.0 & 1.0 \\
\hline FA & 1.2 & 1.2 & 1.2 \\
\hline B & 2.2 & 2.2 & 2.2 \\
\hline FSS & 0.8 & 0.8 & 0.8 \\
\hline SL & 0.18 & 0.18 & 0.18 \\
\hline W & 0.65 & 0.65 & 0.65 \\
\hline HRWR & 0.021 & 0.021 & 0.021 \\
\hline FIBRE & $2.0 \%$ & $2.0 \%$ & $2.9 \%$ \\
\hline W/C & 0.67 & 0.67 & 0.67 \\
\hline W/B & 0.30 & 0.30 & 0.30 \\
\hline Liq./B & 0.31 & 0.31 & 0.31 \\
\hline
\end{tabular}

${ }^{*} C=1.0$;

Supplementary Symbols: $B=C+F A$ (Binding system); $F S S=$ Fine Silica Sand; $S L=$ Slurry Lime; $W-$ Water; HRWR-Superplasticizer; Liq. $=W+H R W R$;
For a better relevance of the study, the matrix mix proportions were kept similar for all the composites, the fresh state aspect allowing for this to happen.

\section{Experimental tests: results and discussions}

\subsection{Mechanical properties}

The classic mechanical characteristics, the flexural and compressive strengths were determined according to EN 196-1 [20] and EN 1015-11 [21] methodologies, at 28 days and also at 56 days; later age testing proved to be relevant for the high content fly ash composites, due to the fly ash's late pozzolanic reaction. $40 \times 40 \times 160 \mathrm{~mm}^{3}$ prismatic specimens, cured according to cementitious materials: removal from the mould 24 hours after casting and kept immersed in water, at $\mathrm{T}(21 \pm 2)^{\circ} \mathrm{C}$ till the testing age, were used for the testing.

a)

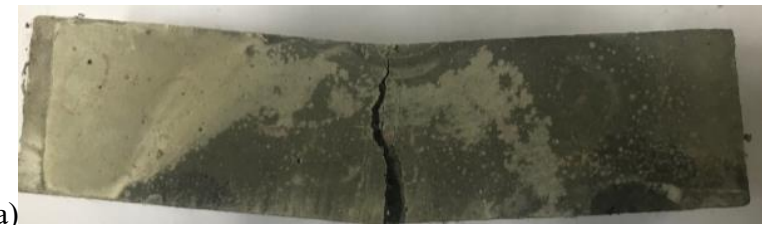

b)

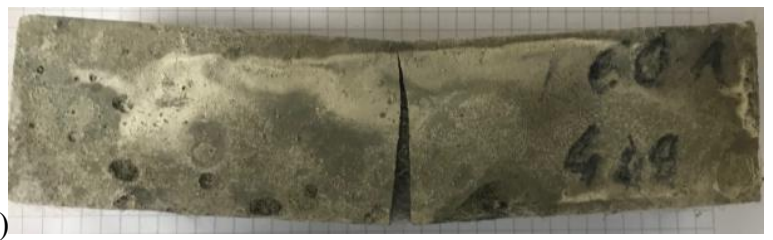

c)

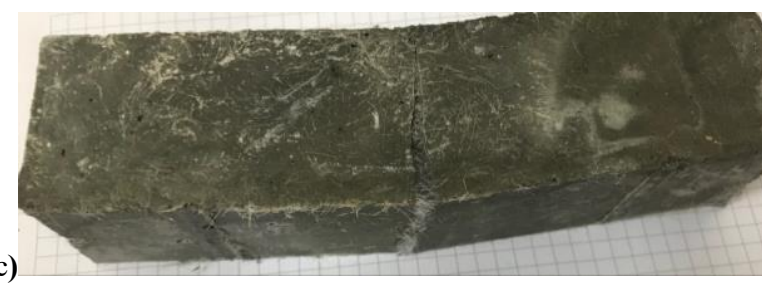

Fig. 5. PVA/PP - FECM, 3PB failure cracking pattern: a) FSSSL-PVA-FA/C (1.2); b) FSS-SL-PP (2.0)-FA/C (1.2); FSS$\mathrm{PP}(2.9)-\mathrm{FA} / \mathrm{C}(1.2)$

Tables 3 and 4 presents the results, in terms of strength and also the strength gain (\%), from 28 days to later age of 56 days. The graphical representation of the results is presented in Fig. 6, (Flexural test) and Fig. 7 (Compression test).

Table 3. Mechanical strengths: 3PB Flexural Resistance.

\begin{tabular}{|c|c|c|c|}
\hline \multirow{2}{*}{$\begin{array}{c}\text { FECM Mix } \\
\text { (PVA\&PP) }\end{array}$} & \multicolumn{3}{|c|}{ 3PB Flexural resistance (MPa) } \\
\cline { 2 - 4 } & $\mathbf{2 8 ~ d}$ & $\mathbf{5 6 ~ d}$ & $\begin{array}{c}\text { Strength } \\
\text { gain (\%) }\end{array}$ \\
\hline $\begin{array}{c}\text { FSS-SL-PVA- } \\
\text { FA/C (1.2) }\end{array}$ & 23.8 & 24.1 & 1.1 \\
\hline $\begin{array}{c}\text { FSS-SL-PP(2.0)- } \\
\text { FA/C (1.2) }\end{array}$ & 13.6 & 14.8 & 8.8 \\
\hline $\begin{array}{c}\text { FSS-SL-PP(2.9)- } \\
\text { FA/C (1.2) }\end{array}$ & 14.0 & 15.9 & 13.2 \\
\hline
\end{tabular}




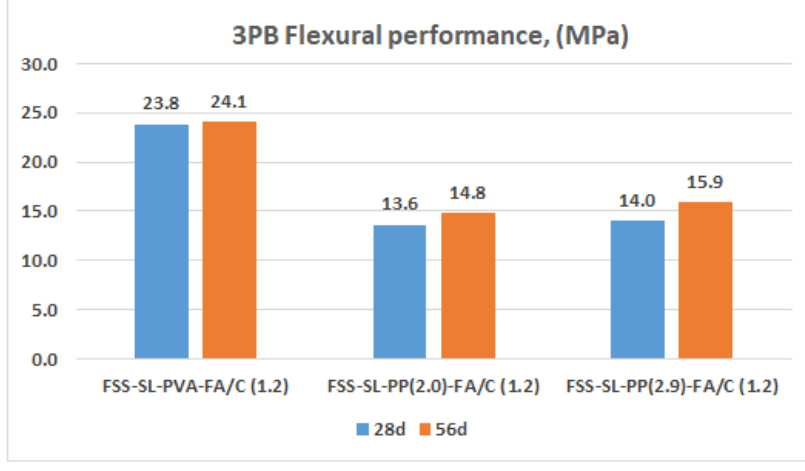

Fig. 6. PVA/PP - FECM, Graphical 3PB Flexural Resistance

The best results were provided, as expected, by the PVA-FECM mix, which developed an impressive flexural strength at 28 days. The value of $23.8 \mathrm{MPa}$ was slightly improved at 56 days - 24.1 MPa. The PP-FECM showed modest results in comparison to the PVA-FECM (designated as control mix for the current evaluation): a flexural strength reduced by $42.8 \%$ for the PP hyb $(2.0 \%) \mathrm{mix}$, and by $41.1 \%$ for the PP hyb $(2.9 \%)$ mix. The PP-FECMs also showed a modest flexural strength gain from 28 to 56 days, of $8.8 \%$ and respectively $13.2 \%$, but slightly better than the $1.1 \%$, of the PVA mix.

The cracking evaluation (Fig. 5) for the PVA composite showed the visible multiple cracking network in the critical zone. For the PP composites, the failure crack tended to be more singular; still, the bridging action of the fibres prevented the integrity loss and ensured the raised flexural strengths of $14-16 \mathrm{MPa}$, which exceeded the normal expectations of a FRC.

The flexural strength evaluation leads to the main conclusion that the extra addition, of almost 1\% (by volume) of PP fibres, is not efficient, not producing a substantial improvement in the overall flexural performance of the material.

Table 4. Mechanical strengths: Compression

\begin{tabular}{|c|c|c|c|}
\hline \multirow{2}{*}{$\begin{array}{c}\text { FECM Mix } \\
\text { (PVA\&PP) }\end{array}$} & \multicolumn{3}{|c|}{ Compression resistance (MPa) } \\
\cline { 2 - 4 } & $\mathbf{2 8 ~ d}$ & $\mathbf{5 6 ~ d}$ & $\begin{array}{c}\text { Strength gain } \\
\text { (\%) }\end{array}$ \\
\hline $\begin{array}{c}\text { FSS-SL-PVA- } \\
\text { FA/C (1.2) }\end{array}$ & 52.5 & 70.6 & 34.4 \\
\hline $\begin{array}{c}\text { FSS-SL-PP(2.0)- } \\
\text { FA/C (1.2) }\end{array}$ & 44.4 & 75.7 & 70.8 \\
\hline $\begin{array}{c}\text { FSS-SL-PP(2.9)- } \\
\text { FA/C (1.2) }\end{array}$ & 47.3 & 77.3 & 63.5 \\
\hline
\end{tabular}

The compressive results collected at 28 days showed almost similar performance of all the PVA / PP-FECMs: $15.6 \%$ and $10 \%$ reduced strengths of the PP mixes with respect to the PVA control mix. The 56 days compressive strength evaluation showed a consistent strength gain for both of the PP mixes, of $70.8 \%$ and $63.5 \%$ with respect to the 28 days evaluation. Opposing this, the PVA mix recorded a rather modest increase, of $34.4 \%$, proving that generally it reaches the maximum bearing capacity around 28 days. On the other hand, the
PP mixes showed a common, later compressive strength gain, with respect to the PVA composite; this behaviour can be attributed only to fibre to matrix physical, mechanical and chemical interaction and bond, clearly distinct from PP to the PVA fibres. Once again, the $2.9 \%$ of PP fibres in the mix failed to prove its efficiency, considering the modest strength gain: $6.2 \%$ (28 days) and $2.1 \%$ (56 days).

The pattern failure prevented the integrity loss due to fibre bridging effect.

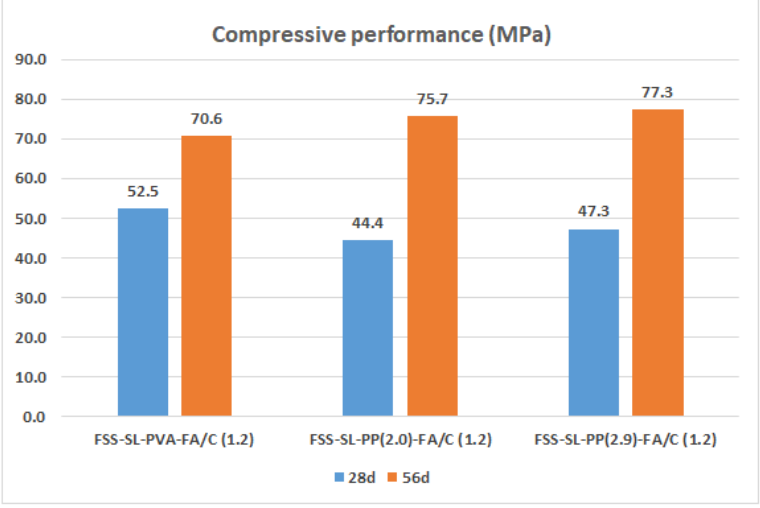

Fig. 7. PVA/PP - FECM, Compressive Strength

The flexural strength evaluation leads to the main conclusion that the extra addition of almost $1 \%$ (by volume) of PP fibres is not efficient, not producing a substantial improvement.

\subsection{Microcracking pattern (MC)}

The composite capacity of developing successive steady state cracks, with narrow opening, is directly connected to the strain hardening, metal like behaviour and therefore to the capacity of deformability, without sudden bearing capacity drop or integrity loss. The multiple cracking (MC) capacity at a certain age is considered to be best evaluated by the flexural 4 point bending test (4PB), performed on coupon specimens (Fig. 8).

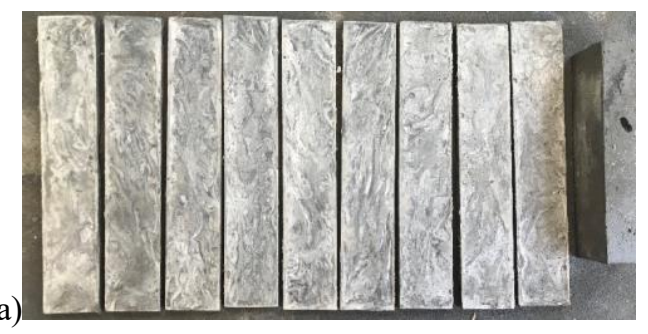

b)

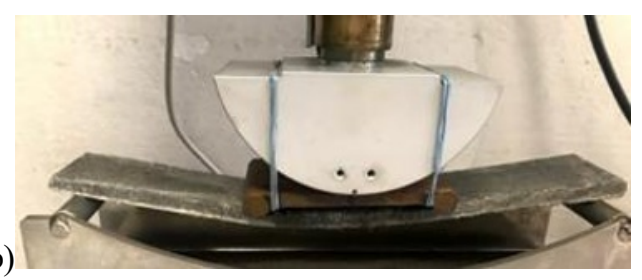

Fig. 8 4PB for PVA - FECM: a) coupon specimens; b) Coupon developing high deformability under loading 
The 4PB test is currently performed on $200 \times 40 \times 8 \mathrm{~mm}^{3}$ (Fig. 8) coupon specimens at the age of 28 days, considered to be relevant for the evaluation.

The specimens were identically cast and cured as the 3PB specimens. The testing device used an adapted 4PB displacement control UNIFRAME MINI (Fig. 2, Fig. 8, b). The crack network was analysed considering the general aspect, the crack numbers and their openings (minimum, mean and maximum values); the crack typology (with or without branches) was also considered. The evaluation was performed on samples containing three coupon specimens / mixture, by using the microscopic visual analyses, namely a stereomicroscope Leica S8 APO, equipped with digital camera Leica DMC2900. The LAS Analysis Bundle software was used to process the data acquired via optical microscopic measurements. The analysis results are summarised in Table 5.

Table 5. Microcracking potential (MC): 4PB testing at characteristic ages of 28

\begin{tabular}{|c|c|c|c|c|}
\hline \multirow{3}{*}{$\begin{array}{l}\text { FECM Mix } \\
\text { (PVA\&PP) }\end{array}$} & \multicolumn{4}{|c|}{ MC interval } \\
\hline & \multirow{2}{*}{$\begin{array}{c}\text { Crack } \\
\text { number } \\
\text { (n) }\end{array}$} & \multicolumn{3}{|c|}{ Crack opening } \\
\hline & & $\begin{array}{c}\mathrm{W}_{\max } \\
(\mu \mathrm{m})\end{array}$ & $\begin{array}{l}\mathrm{W}_{\text {med }} \\
(\mu \mathrm{m})\end{array}$ & $\begin{array}{r}W_{\min } \\
(\mu \mathrm{m})\end{array}$ \\
\hline $\begin{array}{c}\text { FSS-SL-PVA- } \\
\text { FA/C (1.2) }\end{array}$ & $11-13$ & 48 & 29 & 10 \\
\hline $\begin{array}{c}\text { FSS-SL-PP(2.0)- } \\
\text { FA/C (1.2) }\end{array}$ & $2-3$ & 58 & 20 & 34 \\
\hline $\begin{array}{c}\text { FSS-SL-PP(2.9)- } \\
\text { FA/C }(1.2\end{array}$ & $2-3$ & 58 & 20 & 34 \\
\hline
\end{tabular}
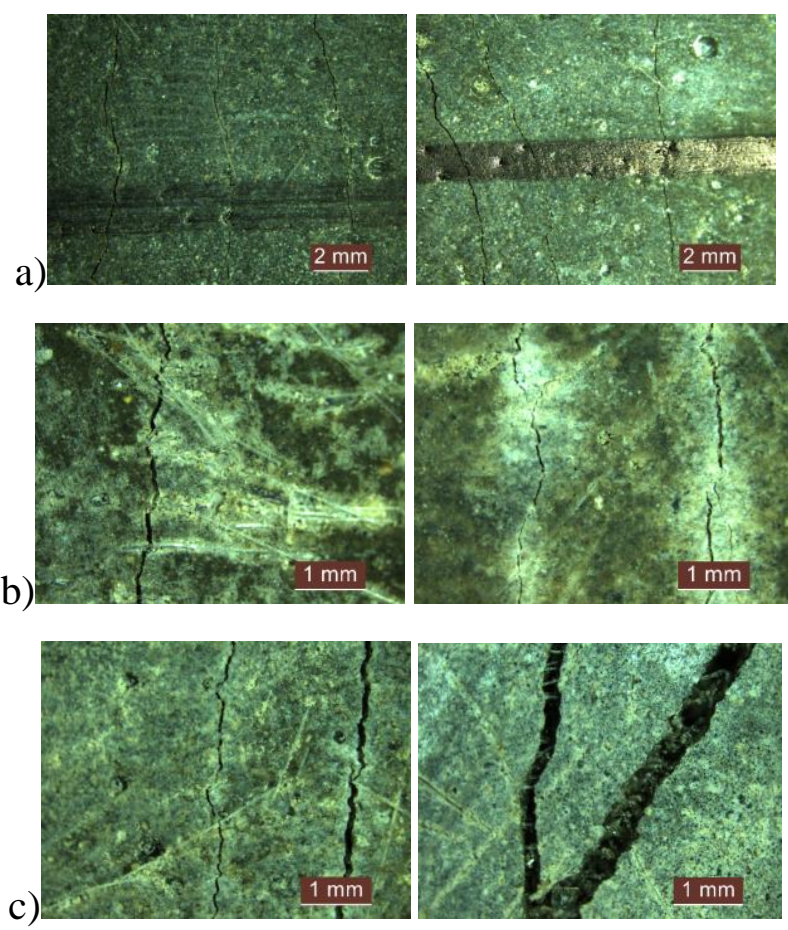

Fig. 8 Microscopic analysis of 4PB cracking pattern: a) FSSSL-PVA-FA/C (1.2); b) FSS-SL-PP (2.0)-FA/C (1.2); FSS$\mathrm{PP}(2.9)-\mathrm{FA} / \mathrm{C}(1.2)$
It was noticed that MC capacity generally degrades over time [2], as the material hardens. Previous studies on PP hyb-FECM mixes (with local PP fibres) [13, 14], despite of the encouraging early age results (3 and 7 days), showed a significant drop in the 28 days $\mathrm{MC}$ capacity (Fig. 2).

The current evaluation was performed directly at the age of 28 days and did not show significant improvement of the PP_hyb-FECMs. The supplementary fibre addition $(2.9 \%$ instead of the typical $2.0 \%)$ did not bring an effective, quantifiable beneficial effect to the composite behaviour. The MC potential was quite scarce, 2-3 cracks in comparison to 11-13 cracks of the lubricated PVA, proving a superior compatibility between PVA and the cementitious matrix, ensuring the strain hardening effect. As expected, brittle failure was avoided for all mixes.

\section{Summary and conclusions}

The experimental procedures for mechanical evaluation of different types of FECMs developed and optimised with mainly local raw materials offer encouraging results. The overall performance of FECM, with PVA $r$ PP fibres as dispersed reinforcement, $2 \%$ (by volume) as optimal fibre content in the mix, proved the viability of the material and its capacity of being tailored in accordance to the necessary specific characteristics, imposed by the potential domain of direct applicability. The study experimentally proved the increased impact of the matrix to fibre compatibility on the complete set of characteristics and material performance. This aspect is essential for design optimising of the composites.

At the same time, the study confirmed that $2 \%$ fibres (by volume) represented the optimum fibre content in the ECC typology of materials. An extra addition of fibres involves increased costs, more mixing difficulties etc., and it does not bring an effective superior performance, which might justify it.

As a supplementary point, the study showed increased potential for the fly ash (FA) valorisation, as main addition to cementitious composites, as cement substitute, with positive overall effect in the matrix synergetic processes and, consequently, for the FA waste prevention as main research goals of Incerc Cluj. [16].

\section{Acknowledgements}

The current experimental program was carried out in the framework of the $\mathrm{PhD}$. Research Program of the first author at the Technical University of Cluj-Napoca. All the experimental work has been carried out in the laboratory of NIRD. URBAN-INCERC, Cluj-Napoca Branch, Romania and was supported by the Research Programmes for Smart Specialization, Sustainable Territorial Development, Environment Preservation and Resilience of Building Heritage - "CONCRET", PN 18 3504 03: "Research for valorising the inert, hydraulic late or pozzolanic mineral additions in innovative cementitious materials for resilient structures, in the context of implementing the "Circular Economy" 
concepts in Romania and PN 193304 02: "Sustainable solutions to ensure health and safety of the population in the open innovation context and environmental protection", financed by the Romanian Government.

\section{References}

1. V.C Li, Engineered Cementitious Composites (ECC) Material, Structural, and Durability Performanc,. in Nawy E. (Editor), Concrete Construction Engineering Handbook, Chapter 24, CRC Press (2008), pp. 1-78

2. D. Snoeck, Self-healing and microstructure of cementitious materials with microfibres and superabsorbent polymer, $\mathrm{PhD}$. Thesis, Ghent University, Ghent, Belgium (2015)

3. L. Vandewalle et al., RILEM TC 162-TDF: test and design methods for steel fibre reinforced concrete: sigma-epsilon-design method-final recommendation, Mater. Struct. 36 (2003), pp. 560567

4. V.C. Li, C.K.Y. Leung, Steady state and multiple cracking of short random fiber composites, ASCE Engineering Mechanics 188 (1992) 11, pp. 22462264

5. V.C. Li, C. Wu., S. Wang, A. Ogawa, T. Saito, Interface Tailoring for Strain-Hardening Polyvinyl Alcohol - Engineered Cementitious Composites (PVA-ECC), ACI Materials Journal 99 (2002) 5, pp. 463-472

6. V.C. Li, H. Stang, H. Krenchel, Micromechanics of Crack Bridging in Fibre-Reinforced Concrete, Materials and Structures 26 (1993) 8, pp. 486-494

7. V.C. Li, S. Wang, C. Wu, Tensile strain-hardening behavior of polyvinyl alcohol engineered cementitious composites (PVA-ECC,) ACI Materials Journal 98 (1997) 6, pp. 483-492

8. V. Mechtcherine, F. de Andrade Silva, M. Butler, D. Zhu, B. Mobasher, S.-L. Gao, E. Mäder, Behaviour of strain-hardening cement-based composites under high strain rates, Journal of Advanced Concrete Technology 9 (2011) 1, pp. 51-62

9. E.-H. Yang, Designing added functions in Engineered Cementitious Composites, University of Michigan, Ann Arbor (2008), pg. 293.

10. E.-H. Yang, Y. Yang, V.C. Li, Use of High Volumes of Fly Ash to Improve ECC Mechanical Properties and Material Greenness, ACI Materials Journal 104 (2007) 6, pp. 303-311

11. V.C. Li, E. Herbert, Robust Self-Healing Concrete for Sustainable Infrastructure, Journal of Advanced Concrete Technology 10 (2012) 6, pp. 207-218

12. D. Snoeck, N. De Belie, Mechanical and selfhealing properties of cementitious composites reinforced with flax and cottonised flax, and compared with polyvinyl alcohol fibres, Biosystems Engineering 111 (2012) 4, pp. 325-335
13. C. Baeră, H. Szilagyi, A. Lăzărescu, Developing Fibre Engineered Cementitious Materials with SelfHealing abilities (SH-FECM) by using polyvinyl alcohol fibres and supplementary powder addition, Wit Derkowski et al. (Eds.), Proceedings of the fib Symposium 2019 held in Kraków, Poland (2019), pp. 387-294

14. C. Baeră, H. Szilágyi, C. Mircea, A. Hegyi, D. Snoeck, Fibre engineered cementitious materials (FECM) optimisation by the use of hybrid polypropelene fibres and supplementary powder addition, Proceedings of the 17th International Multidisciplinary Scientific GeoConference \& EXPO - SGEM 2017, Albena, Bulgaria (2017), pp. 169-176

15. A. Lăzărescu, C. Baeră, H. Szilagyi, A Review on the Development of Fly Ash-Based Geopolymer Materials Using Romanian Local Raw Materials, Proceedings of the EUROCOALASH 2019, Dundee, Scotland, UK (2019), pp. 145-156

16. H. Szilagyi, C. Baeră, A. Hegyi, A. Lăzărescu, Romanian resources of waste and industrial byproducts as additions for cementitious mixtures, Proceedings of the 18th International Multidisciplinary Scientific GeoConference SGEM 2018, 30 June - 9 July, Albena, Bulgaria (2018), pp. 325-332

17. C. Baeră, Self-Healing capacity of Advanced Engineered Cementitious Composites, PhD. Thesis, Technical University of Cluj-Napoca, Cluj-Napoca, Romania (2016)

18. ASRO, SR EN 14889-2:2007 - Fibres for concrete Part 2: Polymer fibres - Definitions, specifications and conformity, Romanian Standards Association, Bucharest, Romania (2007)

19. ASTM, C-1116 - Standard Specification for FiberReinforced Concrete and Shotcrete, American Society for Testing and Materials, USA (2003)

20. ASRO, SR EN 196-1:2016 Methods of testing cement. Determination of strength, Romanian Standards Association, Bucharest, Romania (2016)

21. ASRO, SR EN 1015-11:2002/A1:2007 - Methods of test for mortar for masonry. Determination of flexural and compressive strength of hardened mortar, Romanian Standards Association, Bucharest, Romania (2007) 